\title{
Awe as a Social Emotion: An Overview of Insights from Social Neuroscience and Self-categorisation Theory
}

\author{
Anastasia Ejova \\ University of Adelaide \\ University of Auckland
}

\begin{abstract}
Awe tends to be defined as an emotion characterised by a perception of vastness that challenges or negates existing concepts of the world, creating a "need for accommodation". Emerging research on linguistic labels for awe-like experiences suggests that, while there is no universal word for disorienting experiences of vastness, there is cross-cultural recognition of encountering forces superior to oneself. Under the theory of constructed emotion in social neuroscience, the experience of encountering a force greater than oneself results in behaviour that serves group interests when those interests are part of the perceiver's concept of the vast stimulus. I argue that this is true in most cases, since awe-inspiring charismatic leaders, historical artefacts, and elaborate ceremonies directly represent group interests. Meanwhile, vast natural scenes encourage individuals to conceive of themselves in more superordinate terms (e.g., as human) within the scene. If experiences of awe-inspiring ceremonies, leaders, historical artefacts and natural features have a prosocial component that encourages consideration of group-level interests, it is possible that the "need for accommodation" component of awe is, in many cases, a social process. Within the framework of self-categorisation theory, it might be a process of adopting the identity of a group that is broader than family-based and friendship-based groups that one typically identifies with.
\end{abstract}

\section{Keywords}

awe; prosociality; need for accommodation; small self; theory of constructed emotion; social identity theory

\section{Contact address}

Dr. Anastasia Ejova, School of Psychology, University of Adelaide, Australia; School of Psychology,

University of Auckland, New Zealand; e-mail: anastasia.ejova@mq.edu.au 
Following an influential theoretical article by Dacher Keltner and Jonathan Haidt (2003) in Cognition and Emotion, awe has come to be defined as an emotion characterised by, firstly, a perception of vastness, and, secondly, a need for accommodation - "a challenge to or negation of mental structures when they fail to make sense of an experience of something vast". ${ }^{1}$ Keltner and Haidt further proposed that the perceived vastness and resulting disorienting need for accommodation can make personal concerns feel small relative to the surrounding environment. This proposal that awe fosters a sense of "small self" set off a wave of recent research showing that people reminded of, or presented with, an awe-inspiring experience proceed to act more prosocially, reporting intentions to donate more to charity or stopping to pick up more objects accidentally dropped by a passer-by. ${ }^{2}$ The research has also reignited interest in awe's role as a social glue in the development of civilizations. ${ }^{3}$

Even though findings of a positive awe-prosociality relationship have attracted wide interest, research and theory on awe-driven prosociality are in their infancy. Two sets of findings in social neuroscience indicate that any research into emotion-action relationships is likely to generate variable results with discernible systematic effects of participants' culture-specific beliefs. Firstly, mappings of emotion labels to flavours of experience have been found to vary extensively across languages, and, thus, across cultures. ${ }^{4}$ For example, in English, the word disgust refers to negatively valenced experiences triggered by physical matter as well as moral indignation. Ifalik people in the Pacific distinguish between these experiences, using the word niyabut to describe disgust triggered by physical matter, and the word song to describe moral disgust. Secondly, emotions that are considered distinct in European cultures (e.g., happiness and anger) have been found to activate domain-general conceptual processing systems in the brain (e.g., in the medial prefrontal context) without leaving distinct neural or physiological footprints. ${ }^{5}$ Both of these findings are consistent

${ }^{1}$ Keltner, D., and Haidt, J., "Approaching Awe, A Moral, Spiritual, and Aesthetic Emotion”, Cognition and Emotion, 17, 304. (2003).

${ }^{2}$ Bai, Y. et al., "Awe, the Diminished Self, and Collective Engagement", Journal of Personality and Social Psychology, 113, Studies 5 and 6 (2017); Piff, P. K., et al., "Awe, the Small Self, and Prosocial Behaviour", Journal of Personality and Social Psychology, 108, Studies 2-5 (2015); Shiota, M. N., et al., "The Nature of Awe: Elicitors, Appraisals, and Effects on Self-Concept", Cognition and Emotion, 21, Studies 2 and 4 (2007); Stellar, J. E. et al., "Awe and Humility", Journal of Personality and Social Psychology, 114, Studies 3 and 5 (2018). ${ }^{3}$ Aranyosi, E. F. "Wasteful Advertising and Variance Reduction", Journal of Anthropological Archaeology, 18, 356-375 (1999); Bulbulia, J. "Spreading Order: Religion, Cooperative Niche Construction, and Risky Coordination Problems”, Biology \& Philosophy, 27, 1-27 (2012); Ejova, A. "Awe: A Direct Pathway From Extravagant Displays to Prosociality", Behavioral and Brain Sciences, 39; Johansen, P. G. "Landscape, Monumental Architecture, and Ritual”, Journal of Anthropological Archaeology, 23, 309-330 (2004); Moore, J. D. Architecture and Power in the Ancient Andes, Cambridge University Press, 2 (1996); Wheatley, P. The Pivot of the Four Quarters, Edinburgh University Press, 4 (1971).

${ }^{4}$ Crivelli, C., et al. "Reading Emotions From Faces in Two Indigenous Societies", Journal of Experimental Psychology: General, 145, 830-843 (2016); Gendron, M., et al. "Perceptions of Emotion from Facial Expressions are Not Culturally Universal”, Emotion, 14, 251-262 (2014); Russell, J. A., "Culture and Categorization of Emotions", Psychological Bulletin, 110, 426-450 (1991).

5 Peelen, et al, "Supramodal Representations of Perceived Emotions in the Human Brain", The Journal of Neuroscience, 30, 10127-10134 (2010); Siegel et al., "Emotion Fingerprints or Emotion Populations?”, 
with the theory of constructed emotion, ${ }^{6}$ according to which emotions are concepts mental representations based on past (often, culture-specific) experiences grouped under a goal. Emotion concepts that help people make predictions about impending events and take actions that ensure survival. To quote the theory:

[I]n the past, you have experienced diverse instances of happiness, [such as] lying outdoors on a sunny day, finishing a strenuous workout, hugging a close friend, eating a piece of delectable chocolate or winning a competition. Each instance is different from every other, and when the brain creates a concept of happiness to categorize and make sense of the upcoming sensory events, it constructs a population of simulations... So the brain constructs an on-line concept of happiness, not in absolute terms, but with reference to a particular goal in the situation (to be with friends, to enjoy a meal, to accomplish a task), all in the service of allostasis [internal affective regulation for the purposes of survival] ${ }^{7}$

The limited research that exists on linguistic labels for awe-like experiences is consistent with the possibility that, while there is no universal word for disorienting experiences of vastness, there is cross-cultural recognition of coming in direct contact with forces superior to oneself. For example, the llongot [in the Philippines] use one word, belong, to cover shame, timidity, embarrassment, awe, obedience, and respect. ${ }^{8}$

Meanwhile, the !Kung [of the Kalahari desert] have a word, kua, for the combination of awe, respect, and fear associated with the formally and ceremonially recognized milestones in one's life... [Kua] can also occur in response to danger, such as encountering a lion or walking alone at night. ${ }^{?}$

Perhaps, whether the experience of coming in direct contact with a force greater than oneself results in behaviour that serves group interests depends on whether group interests are part of the perceiver's concept of the vast stimulus. Awe-inspiring charismatic leaders and elaborate ceremonies directly represent group interests. Historical and pre-historical artefacts - which are vast on the dimension of time - represent the interests of humans more broadly. However, as is shown in Figure 1, word association strength mapping within the Small World of Words project ${ }^{10}$ for the English concept of "awe" reveals "nature" as the

Psychological Bulletin, 144, 343-393 (2018).

${ }^{6}$ Barrett, L. F. "The Theory of Constructed Emotion: an Active Inference Account of Interoception and Categorization”, Social Cognitive and Affective Neuroscience, 12, 1-23 (2017).

${ }^{7}$ Barrett, L. F. "The Theory of Constructed Emotion: an Active Inference Account of Interoception and Categorization", 10-11.

${ }^{8}$ Russell, J. A. "Culture and Categorization of Emotions”, 430

${ }^{9}$ Russell, J. A. "Culture and Categorization of Emotions”, 432.

${ }^{10}$ De Deyne, S. et al., "Large-Scale Network Representations of Semantics in the Mental Lexicon”. In M. N. Jones (Ed.), Frontiers of Cognitive Psychology. Big Data in Cognitive Science (174-202). Routledge/Taylor \& Francis Group (2017). 
most closely associated possible elicitor of awe. "Nature" is a general construct not related to any specific social group, although, among indigenous groups, natural spaces are at the centre of community rituals, oral history and group identity. ${ }^{11}$

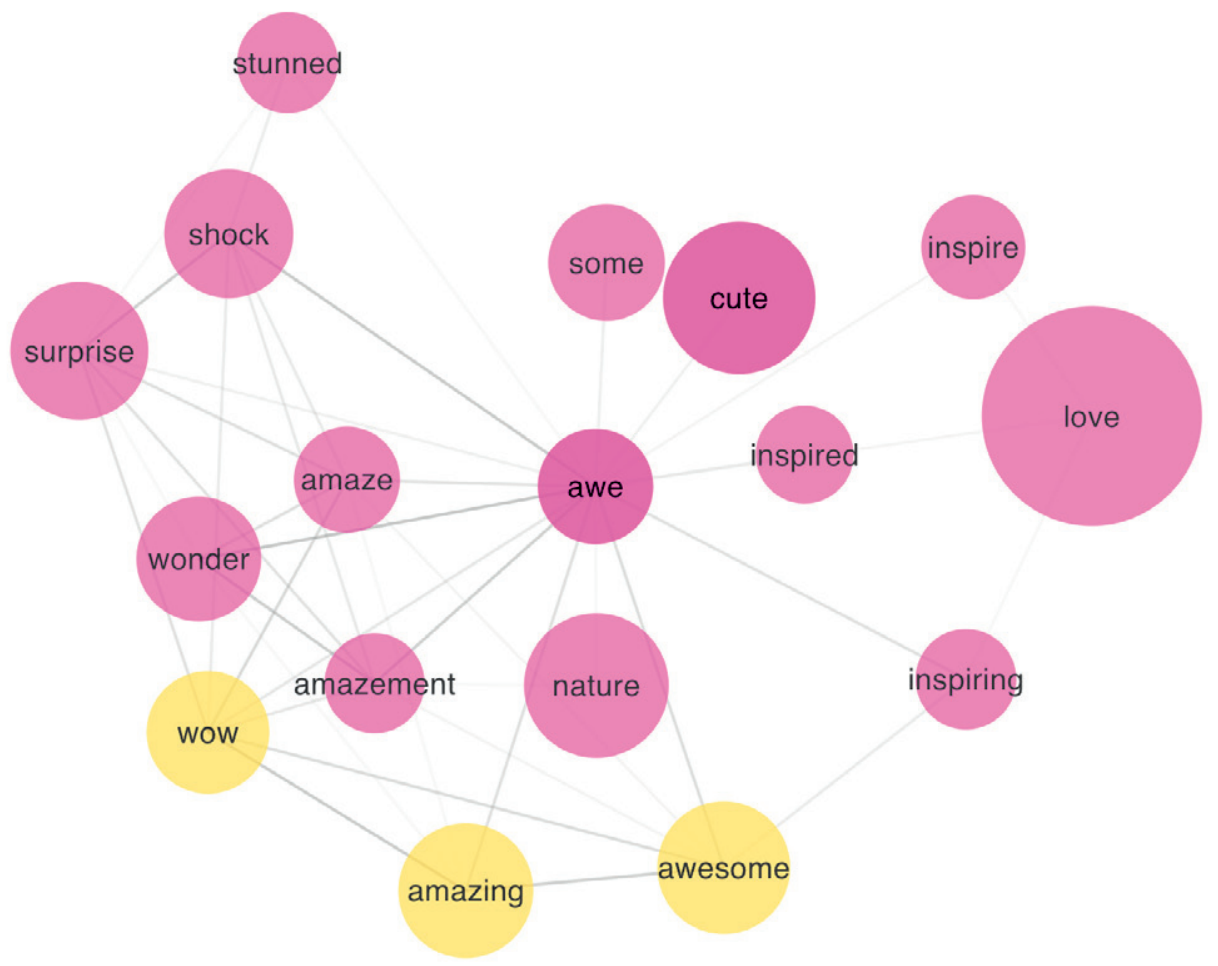

Figure 1. A portion of the associative network around the word "awe" showing direct and indirect neighbouring nodes within the Small World of Words project for the English lexicon. ${ }^{12}$ Larger nodes (circles) are highly connected nodes, or "hubs", within the English lexicon more generally. Different node colours designate "communities" of words - words more densely clustered together. The network describes "forward associations" - words named by participants upon seeing the word "awe" displayed on the screen. Networks of "backward associations" (words eliciting the response "awe") and of bidirectional associations can be viewed on the project website (www. smallworldofwords.org).

With respect to the English-language concept of awe discussed by Keltner and Haidt, the concept's close association with "nature" - a concept that is not inherently social - raises questions over whether cooperative actions are part of the concept. Studies by Murphy and Wisniewski ${ }^{13}$ suggest that, when a physical stimulus - for example, a tree is viewed as part of a scene, the perceiver is faster to recognise it as a representative of a

\footnotetext{
${ }^{11}$ Stevens, S. Conservation through Cultural Survival: Indigenous Peoples and Protected Areas, Island Press. 20-21 (1997).

${ }^{12}$ De Deyne, S. et al., "Large-Scale Network Representations of Semantics in the Mental Lexicon", 174.

${ }^{13}$ Murphy, G. L. and Wisniewski, E. J. "Categorizing Objects in Isolation and in Scenes: What a Superordinate is Good For", Journal of Experimental Psychology: Learning, Memory, and Cogntion, 15, 572-586 (1989).
} 
superordinate category (i.e., as a plant) rather than a basic-level category (i.e., as a tree). For the perceiver of a vast natural landscape that draws attention to the perceiver's size (and, presumably, position) within the scene, thoughts about oneself might, in light of Murphy and Wisniewski's findings, translate into thoughts about oneself as a human rather than an individual person. Humans, by definition, constitute a group.

If experiences of awe-inspiring ceremonies, leaders, historical artefacts and natural features have a prosocial component that encourages consideration of group-level interests, it is possible that the "need for accommodation" component of awe is, in many cases, a social process, and, specifically, one of adopting the identity of a group that is broader than family-based and friendship-based groups that one typically identifies with. Under two influential complementary theories in Social Psychology - social identity theory and self-categorisation theory ${ }^{14}$ - there are many everyday contexts (e.g., the regular quest for takeaway coffee with work colleagues) when people pursue normative group goals rather than personal ones (e.g., with respect to preferred walking speed). In these contexts, people "identify" with, or "self-categorise" into, a particular group. Whether one self-categorises as an individual or a member of a particular group depends on the situation at hand, but also on the extent to which the group has, in the past, allowed one to see oneself in a positive light. Family-based and friendship-based groups are highly accessible for many people, while more abstract self-categorisations (e.g., as a member of the !Kung community or human being) are generally rarer. More abstract self-categorisations might, thus, elicit a need for cognitive accommodation.

Need for accommodation cannot be considered an entirely social process, since it is difficult to imagine that all vast forces encountered by humans throughout history and pre-history have been closely conceptually linked to group interests. Lions - a more individual threat considered an awe-eliciting stimulus among the !Kung - are a case in point. However, in Gordon and colleagues' ${ }^{15}$ study of threat-based awe, many other threat-based stimuli found to elicit awe - images and videos of a powerful tornado, 9/11 terror attacks, and the explosion of the Challenger Space Shuttle - represented, by virtue of their vastness, threats to survival or cooperation potential on a mass (i.e., group) scale. Field studies in Social Psychology have, further, demonstrated that natural disasters ${ }^{16}$ and terror attacks ${ }^{17}$ foster, among affected individuals, identification with "survivors" as a group. Atran and

\footnotetext{
${ }^{14}$ Tajfel, H., and Turner J. C. "An Integrative Theory of Intergroup Conflict", In W. G. Austin \& S. Worchel (Eds.), The Social Psychology of Intergroup Relations (pp. 33-47). Monterey, CA: Brooks/Cole; Turner, J. C. et al., Rediscovering the Social Group: A Self-Categorization Theory, New York: Blackwell (1987); Hornsey, M. J. "Social Identity Theory and Self-Categorization Theory: A Historical Review", Social and Personality Psychology Compass, 2, 204-222 (2008).

${ }^{15}$ Gordon, A.M., et al., "The Dark Side of the Sublime: Distinguishing a Threat-Based Variant of Awe", Journal of Personality and Social Psychology, 113, 310-328. (2016).

${ }^{16}$ Drury, J. et al., "Emergent Social Identity and Observing Social Support Predict Social Support Provided by Survivors in a Disaster", European Journal of Social Psychology, 46, 209-223 (2015).

${ }^{17}$ Drury, Cocking and Reicher, "The Nature of Collective Resilience: Surivor Reactions to the 2005 London Bombings", International Journal of Mass Emergencies and Disasters, 27, 66-95 (2009).
} 
Norenzayan ${ }^{18}$ have, moreover, theorised that, across cultures, communal religious rituals are often targeted at staving off large-scale natural disasters affecting the whole community. Thus, overall, there is emerging consensus that a majority of vast stimuli have social or communal connotations.

Overall, the theory of constructed emotion within social neuroscience draws attention to the context-bound nature of emotion both within and outside the research laboratory. At the same time, the theory does not rule out a positive relationship between experienced vastness on a social, physical or time dimension and short-term or longer-term commitment to group interests. Moreover, in combination with the self-categorisation theory, the constructed-emotion approach allows for the possibility that the need-for-accommodation component of awe is, by definition, a social experience.

\section{Bibliography}

Aranyosi, E. F. (1999). Wasteful advertising and variance reduction: Darwinian models for the significance of nonutilitarian architecture. Journal of Anthropological Archaeology, 18, 356-375.

Atran, S., \& Norenzayan, A. (2004). Religion's evolutionary landscape: Counterintuition, commitment, compassion, communion. Behavioral and Brain Sciences, 27, 713-770.

Bai, Y., Maruskin, L. A., Chen, S., Gordon, A. M., Stellar, J. E., McNeil, G. D., ... Keltner, D. (2017). Awe, the diminished self, and collective engagement: Universals and cultural variations in the small self. Journal of Personality and Social Psychology, 113, 185-209.

Barrett, L. F. (2017). The theory of constructed emotion: an active inference account of interoception and categorization. Social Cognitive and Affective Neuroscience, 12, 1-23.

Bulbulia, J. (2012). Spreading order: religion, cooperative niche construction, and risky coordination problems. Biology \& Philosophy, 27, 1-27.

Crivelli, C., Jarillo, S., Russell, J. A., \& Fernández-Dols, J. M. (2016). Reading emotions from faces in two indigenous societies. Journal of Experimental Psychology: General, 145, 830-843.

Drury, J., Brown, R., González, R., \& Miranda, D. (2015). Emergent social identity and observing social support predict social support provided by survivors in a disaster: Solidarity in the 2010 Chile earthquake. European Journal of Social Psychology, 46, 209-223.

Drury, J., Cocking, C., \& Reicher, S. (2009). The nature of collective resilience: Survivor reactions to the 2005 London bombings. International Journal of Mass Emergencies and Disasters, 27, 66-95.

De Deyne, S., Kenett, Y. N., Anaki, D., Faust, M., \& Navarro, D. (2017). Large-scale network representations of semantics in the mental lexicon. In M. N. Jones (Ed.), Frontiers of cognitive psychology. Big data in cognitive science (pp. 174-202). New York, NY, US: Routledge/Taylor \& Francis Group.

Ejova, A. (2016). Awe: A direct pathway from extravagant displays to prosociality. The Behavioral and Brain Sciences, 39. https://doi.org/10.1017/S0140525X15000424

Gendron, M., Roberson, D., van der Vyver, J. M., \& Barrett, L. F. (2014). Perceptions of emotion from facial expressions are not culturally universal: Evidence from a remote culture. Emotion, 14, 251-262.

${ }^{18}$ Atran, S. and Norenzayan, A. "Religion's Evolutionary Landscape", Behavioral and Brain Sciences, 27, 713-770 (2004). 
Gordon, A. M., Stellar, J. E., Anderson, C. L., McNeil, G. D., Loew, D., \& Keltner, D. (2016). The dark side of the sublime: Distinguishing a threat-based variant of awe. Journal of Personality and Social Psychology, 113, 310-328.

Hornsey, M. J. (2008). Social Identity Theory and Self-Categorization Theory: A historical review. Social and Personality Psychology Compass, 2, 204-222.

Johansen, P. G. (2004). Landscape, monumental architecture, and ritual: a reconsideration of the South Indian ashmounds. Journal of Anthropological Archaeology, 23, 309-330.

Keltner, D., \& Haidt, J. (2003). Approaching awe, a moral, spiritual, and aesthetic emotion. Cognition and Emotion, 17, 297-314.

Moore, J. D. (1996). Architecture and Power in the Ancient Andes - The Archaeology of Public Buildings. Cambridge University Press.

Murphy, G. L., \& Wisniewski, E. J. (1989). Categorizing objects in isolation and in scenes: What a superordinate is good for. Journal of Experimental Psychology: Learning, Memory, and Cogntion, 15, 572-586.

Peelen, M. V., Atkinson, A. P., \& Vuilleumier, P. (2010). Supramodal representations of perceived emotions in the human brain. The Journal of Neuroscience, 30, 10127-10134.

Piff, P. K., Dietze, P., Feinberg, M., Stancato, D. M., \& Keltner, D. (2015). Awe, the small self, and prosocial behavior. Journal of Personality and Social Psychology, 108, 883-899.

Russell, J. A. (1991). Culture and the categorization of emotions. Psychological Bulletin, 110, 426-450.

Shiota, M. N., Keltner, D., \& Mossman, A. (2007). The nature of awe: Elicitors, appraisals, and effects on self-concept. Cognition and Emotion, 21, 944-963.

Siegel, E. H., Sands, M. K., Van den Noortgate, W., Condon, P., Chang, Y., Dy, J., .. Barrett, L. F. (2018). Emotion fingerprints or emotion populations? A meta-analytic investigation of autonomic features of emotion categories. Psychological Bulletin, 144, 343-393.

Stellar, J. E., Gordon, A., Anderson, C. L., Piff, P. K., McNeil, G. D., and Keltner, D. (2018). Awe and humility. Journal of Personality and Social Psychology, 114, 258-269.

Stevens, S. (1997). Conservation through Cultural Survival: Indigenous Peoples and Protected Areas. Covelo, CA: Island Press.

Tajfel, H., \& Turner, J. C. (1979). An integrative theory of intergroup conflict. In W. G. Austin \& S. Worchel (Eds.), The Social Psychology of Intergroup Relations (pp. 33-47). Monterey, CA: Brooks/Cole.

Turner, J. C., Hogg, M. A., Oakes, P. J., Reicher, S. D., \& Wetherell, M. S. (1987). Rediscovering the Social Group: A self-categorization Theory. New York: Blackwell.

Wheatley, P. (1971). The pivot of the four quarters: A preliminary enquiry into the origins and character of the ancient Chinese city. Edinburgh: Edinburgh University Press. 